\title{
PENGEMBANGAN DAN PEMASARAN TERNAK BURUNG PUYUH DI DESA TEGALDOWO GEMOLONG SRAGEN
}

\author{
Eko Meiningsih Susilowati \\ susilowatieko74@gmail.com
}

\begin{abstract}
The high market demand for quail can a promising cattle raising business opportunity. Despite non-primary need of people and its less popularity compared with chicken, catfish, beef cattle, goat, and others, quail breeding business will not subside, but it will keep developing and get more popular. Quail egg is consumed widely by people as it contains high nutrition. The people's high demand for quail egg has not been supported with cattle raisers' knowledge and ability related to business development. It leads to less maximum development of their cattle raising business. This activity was conducted in Wungusari Hamlet, Tegaldowo Village, Gemolong, Sragen. This activity aims to give mentoring to cattle raisers concerning how to breed quail effectively and how to market its product. The methods used were education, lecture, and discussion. The output of current community service activity is that the participants can understand and implement the theory delivered. The number of their cattle increases day by day. Thus, this attempt to develop Quail cattle development has been successful. It can be seen from the increasing result of cattle selling including egg, meat, and manure. The result of activity shows that $80 \%$ of cattle raisers successfully increase their cattle number and get more income due to the ever increasing sale volume.
\end{abstract}

Keywords: development; marketing

\begin{abstract}
Abstrak
Tingkat kebutuhan pasar yang tinggi terhadap burung puyuh dapat dijadikan sebagai peluang usaha beternak yang menjanjikan. Meskipun bukan merupakan kebutuhan pokok hidup orang banyak dan kurang populer dibandingkan dengan ternak ayam, ternak lele, ternak sapi, ternak kambing dan ternak lain-lain, usaha ternak puyuh tidak akan surut, terus berkembang dan semakin memasyarakat. Telur burung puyuh banyak di konsumsi oleh masyarakat karena kandungan gizi yang baik. Jumlah permintaan masyarakat akan telur burung puyuh belum didukung oleh pengetahuan dan kemampuan para peternak mengenai pengembangan usaha. Hal ini berakibat pada tidak maksimalnya perkembangan usaha ternak mereka. Kegiatan ini dilaksanakan di Desa Wungusari, Tegaldowo, Gemolong, Sragen. Tujuan dari kegiatan ini adalah memberikan pembinaan kepada peternak mengenai bagaimana cara beternak burung Puyuh yang efektif untuk pengembangan usaha dan cara pemasarannya. Metode yang digunakan menggunakan edukasi, ceramah dan diskusi. Hasil dari kegiatan pengabdian kepada masyarakat ini adalah para peserta telah dapat memahami dan dapat mengimplementasikan teori yang telah diberikan. Jumlah ternak mereka semakin hari semakin bertambah. Sehingga usaha untuk pengembangan ternak Burung Puyuh berhasil. Hal ini bisa dilihat dari hasil penjualan ternak yang meliputi telur, daging dan kotoran meningkat. Hasil dari kegiatan ini sebanyak $80 \%$ peternak berhasil menambah jumlah ternak dan berhasil pula mendapatkan penghasilan yang lebih banyak karena penjualan yang terus meningkat.
\end{abstract}

Kata Kunci: pengembangan; pemasaran

\begin{tabular}{l|l|l} 
Submitted: $2021-09-25$ & Revised: $2021-10-08$ & Accepted: $2021-10-26$ \\
\hline
\end{tabular}

\section{Pendahuluan}

Masyarakat Indonesia sebagian besar pasti sudah menikmati sedapnya telur puyuh. Puyuh merupakan jenis burung yang tidak dapat terbang, ukuran tubuhnya relatif kecil, berkaki pendek dan dapat diadu. Burung puyuh disebut juga gemak (dalam bahasa Jawa). Bahasa asingnya disebut "Quail", merupakan bangsa burung liar yang pertama kali diternakkan di Amerika Serikat, tahun 1870, dan terus dikembangkan ke penjuru dunia. Sedangkan di Indonesia cara beternak burung puyuh mulai dikenal, dan dikembangkan semenjak akhir tahun 1979. Berternak burung puyuh sangat mudah diterapkan. Dengan tingkat kebutuhan pasar yang tinggi menjadikan burung puyuh ini sebagai peluang usaha yang menjanjikan. Meskipun bukan merupakan kebutuhan pokok hidup orang banyak dan kurang populer dibandingkan dengan ternak ayam, ternak lele, ternak sapi, ternak kambing dan ternak lain-lain, usaha ternak puyuh tidak akan surut, terus berkembang dan semakin memasyarakat. Di Desa Wungusari Tegaldowo, Gemolong, Sragen terdapat banyak 
peternak. Di desa tersebut merupakan tempat yang cocok untuk beternak Burung Puyuh. Desa itu memiliki akses jalan yang mudah untuk menjual hasil produksi dan mudah dalam mencari pakan untuk ternak tersebut. Didukung dengan suasana desa yang tidak bising oleh lalu lalang kendaraan bermotor. Sehingga para peternak mempunyai kesempatan yang banyak untuk mengembangkan usaha.

Permintaan telur burung puyuh semakin hari semakin meningkat seiring dengan bertambahnya jumlah penduduk. Dengan kandungan gizi yang cukup baik, telur burung puyuh banyak di konsumsi oleh masyarakat kita. Tetapi dari jumlah permintaan masyarakat akan telur burung puyuh tersebut belum didukung oleh pengetahuan dan kemampuan para peternak mengenai pengembangan usaha. Hal ini berakibat pada tidak maksimalnya perkembangan usaha ternak puyuh. Saat ini banyak peternak yang hanya bisa beroperasi saja tanpa memikirkan sejauh mana tingkat perkembangan usaha mereka. Karena itu akan dibahas mengenai bagaimana cara pengembangan usaha ternak puyuh tersebut.

Tujuan dari kegiatan ini adalah memberikan pembinaan tentang bagaimana cara beternak burung puyuh yang efektif dan untuk pengembangan usaha dan cara pemasarannya. Kegiatan ini diharapkan dapat memotivasi masyarakat sekitar yang tertarik untuk berternak burung puyuh. Kegiatan ini juga diharapkan dapat digunakan sebagai pedoman bagi peternak puyuh untuk pengembangan usaha.

Penelitian (Rohmaniyah dan Nurhayati, 2017) memberikan hasil orientasi pasar berpengaruh positif dan signifikan terhadap kreativitas pemasaran, kualitas jaringan dan kinerja pemasaran. Hal ini berarti semakin tinggi orientasi pasar, perusahaan dapat mengetahui, memahami, dan memenuhi kebutuhan dan harapan pelanggan, sehingga dibutuhkan kreativitas pemasaran dan kualitas jaringan yang baik bisa untuk meningkatkan kinerja pemasaran perusahaan. Ini dapat dilakukan dengan melihat frekuensi pertemuan dengan pelanggan, interaksi dengan pelanggan, berbicara tentang taktik dan strategi pesaing, mengadakan pertemuan untuk membahas perkembangan pasar, serta tanggap terhadap perubahan harga pesaing.

Penelitian (Destia, dkk, 2017) hasilnya adalah ukuran kandang berpengaruh terhadap konsumsi ransum, rata-rata bobot telur, konversi ransum, quail day production dan jumlah bobot telur puyuh, sehingga dapat meningkatkan produktivitas puyuh pada periode produksi. Hasil penelitian yang dilakukan (Damayanti, dkk, 2018) adalah pemberian pakan komersial yang ditambahkan dengan tepung jintan memberikan pengaruh yang nyata pada rata-rata bobot telur. Sedangkan penelitian (Lubis, (2014) menghasilkan suplementasi selenium organik dan vitamin $E$ dalam pakan induk dapat memperbaiki performa anak. Hal ini dapat dilihat dari peningkatan bobot tetas anak dan penurunan mortalitas. Hasil penelitian (Basharta dan Sudrajat, 2017) pemberian tepung jahe dan tepung kunyit tidak berpengaruh terhadap konsumsi pakan, bobot telur, konversi pakan, deplesi, dan produksi telur puyuh periode layer, tetapi hanya dengan pemberian tepung jahe saja dapat meningkatkan produksi telur. Sedangkan penelitian yang dilakukan (Fadila , dkk, 2018) hasilnya adalah penambahan tepung bawang putih pada pakan dapat meningkatkan kualitas telur puyuh terutama pada kualitas warna kuning telur puyuh.

\section{Metode}

Khalayak sasaran kegiatan adalah para warga di Desa Wungusari RT 16, Tegaldowo, Gemolong, Sragen. Peserta sebanyak 12 orang. Dari latar belakang peserta adalah para warga yang berprofesi sebagai peternak Burung Puyuh. Kegiatan dilakukan di rumah Ibu Endang di Desa Wungusari RT 16, Tegaldowo, Gemolong, Sragen pada tanggal 17 September 2013.

Metode yang dipakai dalam pengabdian ini adalah edukasi, ceramah dan diskusi. Dalam hal ini dilakukan dengan cara memberikan pemahaman tentang bagaimana cara beternak burung puyuh yang efektif dan bagaimana cara untuk melakukan pengembangan usaha dan cara 
pemasarannya, serta dengan memberikan kesempatan kepada peserta untuk mengajukan pertanyaan mengenai hal-hal belum mereka dipahami mengenai materi yang telah disampaikan.

Evaluasi kegiatan dilakukan dengan melihat kemajuan yang terjadi. Kemajuan yang terjadi setelah adanya kegiatan pengabdian kepada masyarakat dengan sebelum adanya kegiatan pengabdian kepada masyarakat.

Materi kegiatan yang diberikan pada kegiatan ini meliputi cara pembuatan kandang yang ideal, cara pemberian pakan dan vitamin yang sesuai, cara pemeliharaan, cara pengembangan usaha, dan cara pemasaran yang efektif.

\section{Hasil dan Pembahasan}

Hasil dari kegiatan pengabdian kepada masyarakat ini adalah para peserta dapat memahami dan dapat mengimplementasikan teori yang telah diberikan. Melalui pendampingan semakin hari jumlah ternak mereka semakin banyak, sehingga usaha untuk pengembangan ternak Burung Puyuh berhasil. Hal ini bisa dilihat dari semakin bertambahnya jumlah ternak dan penjualan hasil ternak yang meliputi telur, daging dan kotoran meningkat. Peningkatan jumlah ternak dan peningkatan jumlah penjualan ini karena didukung dengan pemasaran yang lebih luas. Gambar 1 berikut memperlihatkan kandang ternak Burung Puyuh.

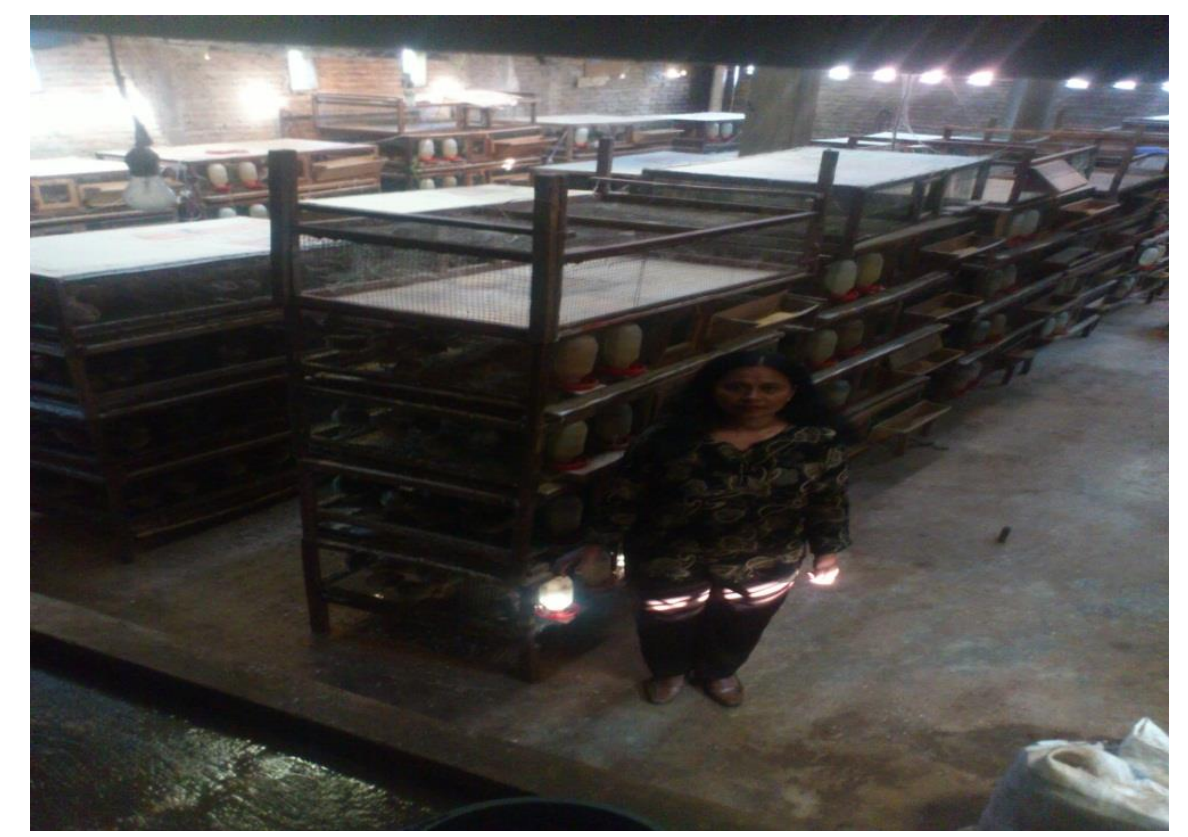

Gambar 1. Kandang Ternak Burung Puyuh

Kegiatan ini adalah berupa kegiatan untuk pengembangan usaha yaitu usaha ternak Burung Puyuh yang berada di Desa Wungusari, Tegaldowo, Gemolong, Sragen. Untuk mengembangkan usaha dilakukan dengan cara menambah jumlah ternak agar lebih banyak. Karena adanya ternak yang lebih banyak akan lebih menguntungkan. Ini berarti jumlah ternak yang lebih banyak akan menghasilkan jumlah telur yang lebih banyak. Dengan hasil telur yang lebih banyak jumlah penjualan akan meningkat, sehingga penghasilan yang diperoleh dapat bertambah. Tidak lupa harus selalu menjaga kebersihan kandang agar ternak terhindar dari suatu penyakit. Termasuk memberikan vitamin dan makanan yang cukup dengan harapan hasil yang diperoleh tetap stabil dan kalau bisa bertambah. Dari hasil kegiatan ini $80 \%$ peternak berhasil menambah jumlah ternak 
mereka dan berhasil pula mendapatkan penghasilan yang lebih banyak. Pada Gambar 2 memperlihatkan hasil telur Burung Puyuh.

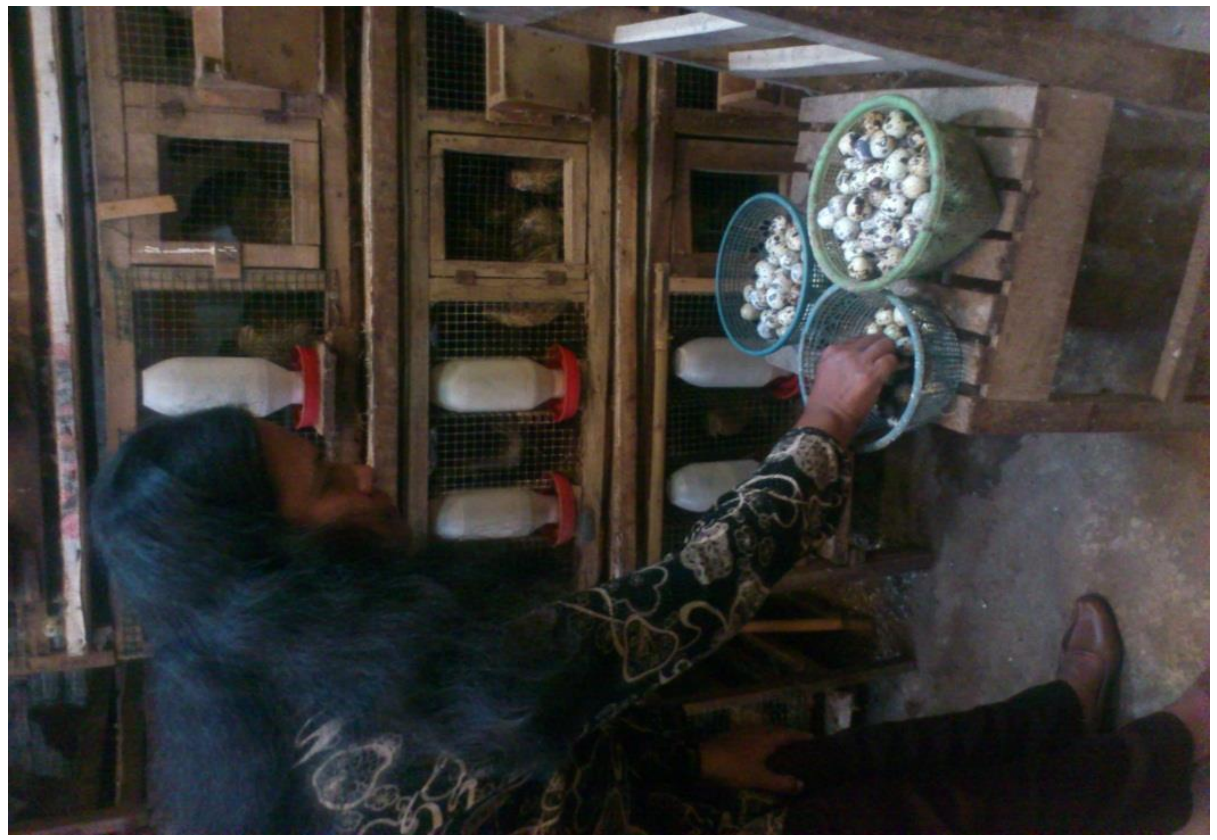

Gambar 2. Hasil Telur Burung Puyuh

\section{Kesimpulan}

Kesimpulan adalah pemberian edukasi dan materi yang telah diberikan dapat meningkatkan pengetahuan para peserta di Desa Wungusari RT 16 Tegaldowo, Gemolong, Sragen dalam mengembangkan dan memasarkan ternak Burung Puyuh. Saran yaitu kegiatan ini dapat dilakukan secara rutin untuk pengembangan usaha yang lebih maju lagi.

\section{Daftar Pustaka}

Basharta, S, Nur, H, dan Sudrajat, D. (2017). Pemberian Tepung Jahe (Zingiber Officinale) Dan Tepung Kunyit (Curcuma Domestica) Pada Pakan Komersial Terhadap Performa Puyuh (Coturnix Coturnix Japonica) Periode Layer. Jurnal Peternakan Nusantara, 103-109.

Damayanti, F, Nur, H, Anggraeni. (2018). Pemberian Tepung Bawang Putih Dan Tepung Jintan Pada Pakan Komersial Terhadap Performa Puyuh (Coturnix Coturnix Japonica) Periode Awal Produksi. Jurnal Peternakan Nusantara, 1-12.

Destia, M, Sudrajat, D, Dihansih, E. (2017). Pengaruh Rasio Panjang Dan Lebar Kandang Terhadap Produktivitas Burung Puyuh. Jurnal Peternakan Nusantara, 57-64.

Fadila, U, Kardaya, D dan Dihansih, E. (2018). Kualitas Telur Puyuh (Coturnix Coturnix Japonica) Yang Diberi Pakan Komersial Dengan Penambahan Tepung Bawang Putih Dantepung Jintan. Jurnal Peternakan Nusantara, 19-24.

Lubis, F. (2014). Suplementasi Selenium Organik dan Vitamin E dalam Pakan Induk terhadap. Jurnal Peternakan Nusantara, 65-74.

Rohmaniyah, A dan Nurhayati, T. (2017). Peningkatan Kreativitas Pemasaran Dan Kualitas Networking Berbasis Orientasi. Ekobis, 149-163. 